\title{
Hypersecretion of corticotrophin-releasing hormone and arginine vasopressin in hypothyroid male rats as estimated with push-pull perfusion
}

\author{
A Tohei, G Watanabe and K Taya \\ Laboratory of Veterinary Physiology, Tokyo University of Agriculture and Technology, Fuchu, Tokyo 183, Japan \\ (Requests for offprints should be addressed to A Tohei, Laboratory of Veterinary Physiology, Tokyo University of Agriculture and Technology 3-5-8, \\ Saiwai-cho, Fuchu, Tokyo 183, Japan)
}

\begin{abstract}
The relationship between hypothyroidism and disturbance of the hypothalamo-hypophysial-adrenal axis was investigated using adult male rats. Hypothyroidism was produced by administration of 4-methyl-2-thiouracil (thiouracil) in the drinking water for 2 weeks. Hypothyroidism decreased adrenal weights to $57 \%$ of controls and plasma concentrations of corticosterone to $48 \%$ of controls. The changes in the weight of adrenals recovered to control levels by administration of thyroxine. The pituitary responsiveness to corticotrophin-releasing hormone $(\mathrm{CRH})$ and arginine vasopressin (AVP) for ACTH release markedly increased
\end{abstract}

in hypothyroid rats as compared with euthyroid rats. In vivo release of $\mathrm{CRH}$ and $\mathrm{AVP}$ in median eminence significantly increased in hypothyroid rats as compared with euthyroid rats. There were no significant differences in hypothalamic concentrations of CRH and AVP.

These results indicate that hypothyroidism causes adrenal dysfunction directly and results in hypersecretion of ACTH mediated by increases in synthesis of CRH and AVP in the hypothalamus.

Journal of Endocrinology (1998) 156, 395-400

\section{Introduction}

Thyroid hormone is important for the growth, development and metabolism of many tissues. It has been shown to play an important role in adrenal function. Hypothyroidism has been reported to reduce the weight of adrenals (McCarthy et al. 1959, Kamilaris et al. 1991) and the plasma concentration of corticosterone, and to affect circadian adrenocortical rhythm (Murakami et al. 1984). In contrast, excess amounts of thyroid hormone increases the weight of adrenals (Boler \& Moore 1982). Thyroidectomy decreases plasma and pituitary adrenocorticotropic hormone (ACTH) levels (Murakami et al. 1984), and causes a reduction in corticotrophin-releasing hormone (CRH) gene transcription (Shi et al. 1994) in the hypothalamic paraventricular nucleus $(\mathrm{PVN})$. On the other hand, recent reports show that the pituitary content of ACTH increases (Tohei et al. 1997) and that ACTH responses to exogenous $\mathrm{CRH}$ are exaggerated in hypothyroid rats (Kamilaris et al. 1991, Tohei et al. 1997). Although it is obvious that thyroid hormone affects the hypothalamo-hypophysialadrenal axis, the site of action of thyroid hormone on this axis is not clearly understood.

In order to clarify the hypothalamo-hypophysialadrenal axis activity in hypothyroid rats, the pituitary responsiveness to $\mathrm{CRH}$ and (AVP) for $\mathrm{ACTH}$ release were examined in the present study. CRH and AVP release in median eminence (ME) were also measured directly using a push-pull perfusion method in adult male hypothyroid rats.

\section{Materials and Methods}

Animals

Adult male rats (350-400 g) of the Wistar strain were used throughout the present study. Animals were maintained with a ratio of $14 \mathrm{~h}$ light: $10 \mathrm{~h}$ darkness (lights on at $0500 \mathrm{~h}$ ). The room was kept between 23 and $26^{\circ} \mathrm{C}$. Rats received a standard laboratory diet and water and were allowed to feed ad libitum. Five animals of each group were used in the present experiment. Hypothyroidism was induced by administration of 0.03\% 4-methyl-2-thiouracil (thiouracil; Wako Pure Chemical Industries Ltd, Osaka, Japan) in the drinking water for 2 weeks. Thyroid hormone replacement was performed daily by intraperitoneal (i.p.) injection of L-thyroxine (T4; $15 \mu \mathrm{g}$ per rat, Sigma Chemical Co., St Louis, MO, USA) for 1 week before the experiment. Twenty-four hours before each experiment, a cannula (Dow Corning, Midland, MI, USA) was inserted into the right atrium via the external jugular vein in each rat for drawing blood samples. Blood $(200 \mu \mathrm{l})$ was 
withdrawn through the atrial cannula into a heparinized syringe without anaesthesia. After separation of the plasma by centrifugation at $1700 \mathrm{~g}$ for $15 \mathrm{~min}$ at $4{ }^{\circ} \mathrm{C}$, the red blood cells were resuspended in the same volume of $0.85 \%$ $(\mathrm{w} / \mathrm{v}) \mathrm{NaCl}$ solution (saline) and returned to the animal through the cannula.

\section{Effects of thiouracil on the thyroid gland and pituitary-adrenal axis}

To confirm the effects of hypothyroidism on the thyroid and adrenal gland, animals were killed by decapitation at 0900 h 2 weeks after administration of thiouracil. Blood was collected and centrifuged for the determination of plasma concentrations of tri-iodothyronine (T3), T4, thyroid stimulating hormone (TSH), ACTH and corticosterone. After decapitation, the adrenal glands and the hypothalami were removed and weighed. The hypothalamus was defined by the optic chiasm anteriorly, the mammillary bodies posteriorly and the lateral hypothalamic grooves; tissue was taken to a depth of $5 \mathrm{~mm}$, according to a previous report (Canny et al. 1988). The hypothalamus was homogenized and centrifuged at $25000 \boldsymbol{g}$ for $30 \mathrm{~min}$ at $4{ }^{\circ} \mathrm{C}$. Supernatants were stored at $-50{ }^{\circ} \mathrm{C}$ until assayed for CRH and AVP.

To investigate the pituitary responsiveness to $\mathrm{CRH}$ and AVP, CRH and AVP challenges were performed 2 weeks after administration of thiouracil. CRH (1 or $10 \mu \mathrm{g}$, Peptide Institute Inc., Osaka, Japan) and AVP $(0 \cdot 1$ or $1 \mu \mathrm{g}$, Peptide Institute Inc.) dissolved in $0.2 \mathrm{ml}$ saline were injected through the cannula at $0900 \mathrm{~h}$. Control animals received the same volume of vehicle. Blood samples for plasma ACTH determinations were drawn from the cannula immediately before injection and $0 \cdot 5,1,2$ and $3 \mathrm{~h}$ after injection of CRH and 5, 10, 15, 30, 45 and $60 \mathrm{~min}$ after injection of AVP.

\section{Push-pull perfusion protocol}

Animals were anaesthetized with sodium pentobarbital $(40 \mathrm{mg} / \mathrm{kg})$ and placed in a stereotaxic apparatus to implant the guide cannula with a removable stylette into the ME. Implantation coordinates (Paxinos \& Watson 1986) were $-3.14 \mathrm{~mm}$ anterior, $-0.1 \mathrm{~mm}$ lateral and $-10 \cdot 2 \mathrm{~mm}$ ventral from bregma for ME. The cannula was fixed onto the skull with anchor screws and dental cement. Animals were given a minimum recovery period of 7 days. On the day of push-pull perfusion, the inner stylette was removed and replaced with the inner cannula perfusion assembly. Artificial cerebrospinal fluid (Watanobe \& Takebe 1994) was administered through the push cannula at a flow rate of $15 \mu \mathrm{l} / \mathrm{min}$. Perfusion fractions $(300 \mu \mathrm{l})$ were collected every 20 min over a total period of $180 \mathrm{~min}(1830-2130 \mathrm{~h})$. The perfusates were immediately frozen on dry ice and lyophilized. After completion of experiments, each animal was anaesthetized with ether and subjected to vascular perfusion with $0.9 \%$ (w/v) $\mathrm{NaCl}$, followed by $10 \%$ formol-saline. The brain was removed and soaked in 10\% formol-saline for 3 days. Frozen $\left(-20^{\circ} \mathrm{C}\right)$ serial $40-\mu \mathrm{m}$ sections were cut along the plane of the cannula tract and stained with cresyl violet to confirm the position of the cannula.

\section{Radioimmunoassay (RIA)}

Concentrations of TSH were measured using NIDDK rat RIA kits for rat TSH. Hormone for iodination was rat TSH-I-9 and the antisera used were anti-rat TSH-S-5. Results were expressed in terms of NIDDK rat TSH$\mathrm{RP}-2$. The intra- and interassay coefficients of variation were 6.6 and $7.9 \%$ respectively.

T3, T4 (Tohei et al. 1997), ACTH (Tomabechi et al. 1994), corticosterone (Kanesaka et al. 1992) and CRH (Suda et al. 1987) were measured by double-antibody RIAs using ${ }^{125}$ I-labelled radioligands as described previously. Antisera to T3 and T4 were kindly provided by Dr M Suzuki (Gunma University, Maebashi, Gunma, Japan). Antiserum to corticosterone was kindly provided by Dr GD. Niswender (Colorado State University, Fortcollins, CO, USA). Antiserum to CRH was kindly provided by Dr T Suda (Hirosaki University, Aomori, Japan). The intra- and interassay coefficients of variation were $7 \cdot 2$ and $17.4 \%$ for $\mathrm{T} 3,9.4$ and $10.9 \%$ for $\mathrm{T} 4,11.3$ and $11.9 \%$ for ACTH, $9 \cdot 8$ and $17 \cdot 5 \%$ for corticosterone, and $5 \cdot 5$ and $11 \cdot 2 \%$ for CRH respectively. AVP was measured by a commercial RIA kit purchased from Mitsubishi Chemical Corporation (Tokyo, Japan). The detection limits (defined as the amount of hormone that reduced binding to $85 \%$ of that occurring in the absence of unlabelled hormone) were $1 \mathrm{pg} /$ tube for CRH and $0 \cdot 1 \mathrm{pg} /$ tube for AVP.

\section{Statistical analyses}

All results are expressed as means \pm S.E.M. The data of plasma concentrations of T3, T4, TSH and hypothalamic concentrations of $\mathrm{CRH}$ and AVP were analyzed by Student's $t$-test but when more than two means were compared, an ANOVA was carried out and significance of the difference between means was determined by Duncan's multiple range test. The data of organ weight and plasma concentration of corticosterone were analyzed using one-way analysis of variance (ANOVA) followed by Fisher's protected least significant difference (PLSD) test. The effects of CRH and AVP challenges and the hypothalamic secretion of $\mathrm{CRH}$ and AVP were analyzed using two-way ANOVA followed by Fisher's PLSD test; a value of $P<0 \cdot 05$ was considered significant.

\section{Results}

Effects of thiouracil on thyroid gland and pituitary-adrenal axis Plasma concentrations of $\mathrm{T} 3$ and $\mathrm{T} 4$ were markedly suppressed (T3, from 464 to $76 \cdot 8 \mathrm{pg} / \mathrm{ml}$; $\mathrm{T} 4,37 \cdot 2$ to 
$9 \cdot 8 \mathrm{ng} / \mathrm{ml}$ ) in male rats 2 weeks after administration of thiouracil. On the other hand, the plasma concentration of TSH in hypothyroid rats was significantly increased (from 0.76 to $7.26 \mathrm{ng} / \mathrm{ml}$ ) as a result of administration of thiouracil (Fig. 1).

Adrenal weights and plasma concentrations of corticosterone were significantly lower in hypothyroid rats $(35.62 \mathrm{mg}$ and $35 \mathrm{ng} / \mathrm{ml})$ as compared with intact rats $(61.34 \mathrm{mg}$ and $72.6 \mathrm{ng} / \mathrm{ml})$. These changes recovered to control levels $(57.28 \mathrm{mg}$ and $84.6 \mathrm{ng} / \mathrm{ml}$ ) after administration of T4 (Fig. 2).

In response to two doses of $\mathrm{CRH}$, plasma levels of ACTH increased and reached a peak by 15 min after the injection in both groups of animals. The pituitary response to $\mathrm{CRH}$ for $\mathrm{ACTH}$ release was higher at high dose $(10 \mu \mathrm{g})$ in hypothyroid than euthyroid rats, although there was no significant difference in low dose $(1 \mu \mathrm{g}) \mathrm{CRH}-$ injected groups. In response to two doses of AVP, plasma levels of ACTH increased and reached a peak by 5 or $10 \mathrm{~min}$ after the injection in both groups of animals. The pituitary response to AVP was higher with both doses $(0 \cdot 1$ and $1 \mu \mathrm{g}$ ) in hypothyroid than in euthyroid rats (Fig. 3).

\section{Hypothalamic secretion of $C R H$ and AVP as estimated with push-pull perfusion}

In vivo release of $\mathrm{CRH}$ and AVP in ME by push-pull perfusion significantly increased in hypothyroid rats as compared with euthyroid rats (Fig. 4). There were no significant differences in hypothalamic concentrations of $\mathrm{CRH}$ and AVP (Fig. 5).

\section{Discussion}

In the present study, we observed decreases in adrenal weights and basal levels of plasma corticosterone in hypothyroid male rats at 2 weeks after administration of thiouracil. These changes in adrenal weights recovered to control levels by administration of T4. It has been reported that adrenal responsiveness to ACTH also decreased in hypothyroid rats (Tohei et al. 1997). Our present findings are supported by previous reports (McCarthy et al. 1959, Murakami et al. 1984).

The pituitary responsiveness to CRH and AVP for ACTH release significantly increased in hypothyroid rats as compared with control rats. We have previously reported that pituitary contents of ACTH also increased in hypothyroid male rats and the change recovered to control levels after administration of T4 (Tohei et al. 1997). Previous reports regarding the effect of hypothyroidism on ACTH secretion are conflicting. Murakami et al. (1984) reported that thyroidectomy resulted in a decrease in plasma and pituitary levels of ACTH in female rats. On the other hand, most recent reports have shown that ACTH responses to exogenous CRH were exaggerated,

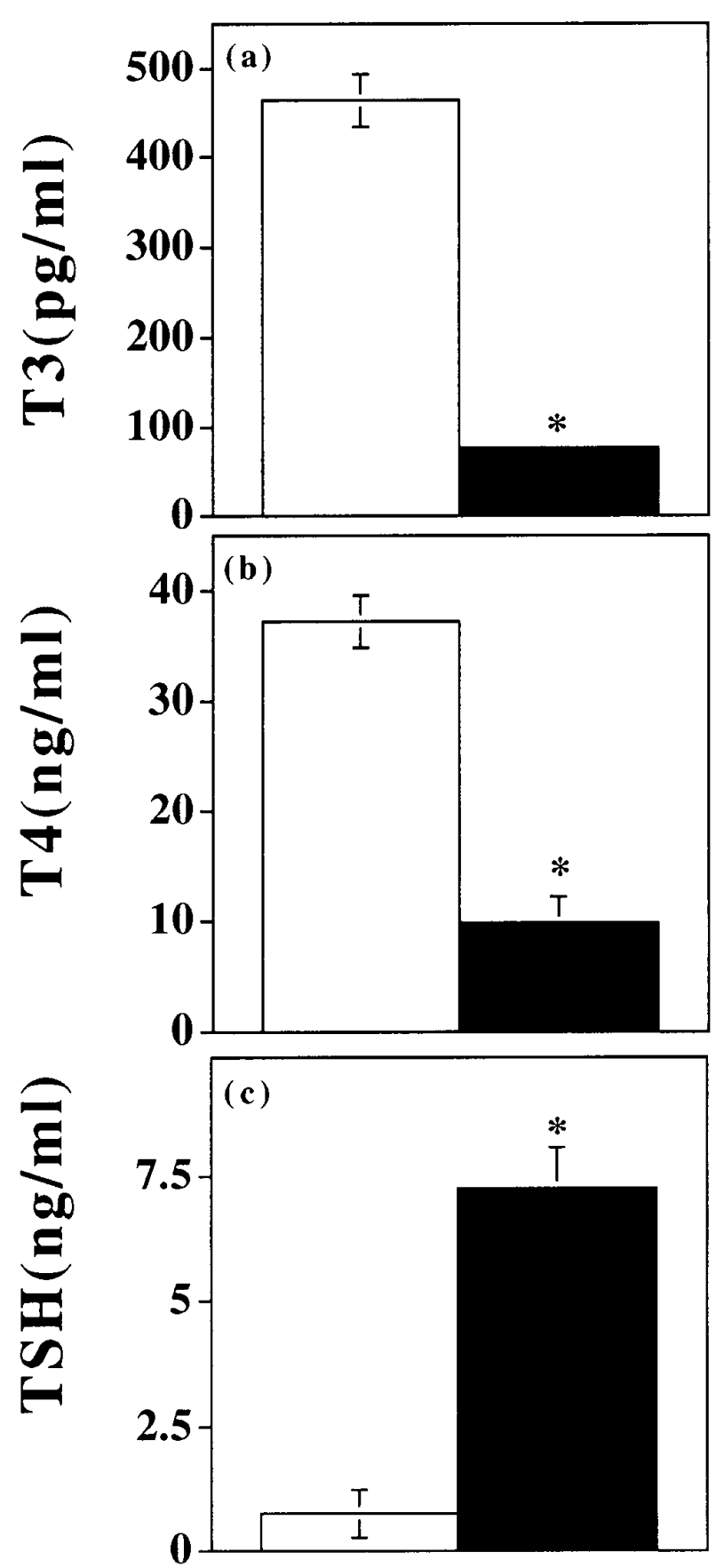

Figure 1 Plasma levels of (a) T3, (b) T4 and (c) TSH in thiouracil treated rats (solid bars) and control rats (open bars). Asterisks indicate $P<0.05$ compared with the value for the respective control (Student's t-test).

while corticosterone responses to ACTH were reduced in hypothyroid male rats (Kamilaris et al. 1991, Tohei et al. 1997). Other reports have shown that under conditions of stress, a marked increase in plasma levels of ACTH in 

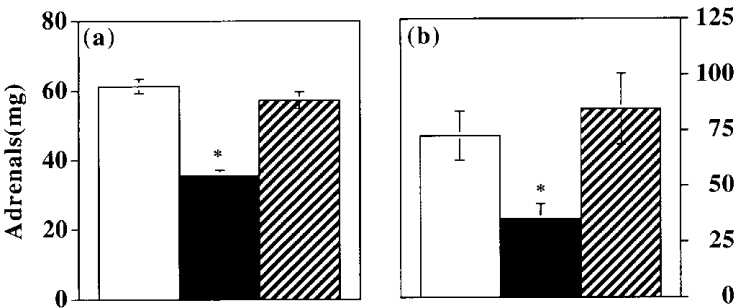

Figure 2 Weights of adrenal glands (a) and plasma concentrations of corticosterone (b) in control (open bars), 2-week thiouraciltreated (solid bars) and thiouracil- and T4- (1-week) treated (hatched bars) rats. Each bar represents the mean \pm S.E.M. of five animals. Asterisks indicate $P<0.05$ compared with the value for the respective control (one-way ANOVA followed by Fisher's PLSD test).
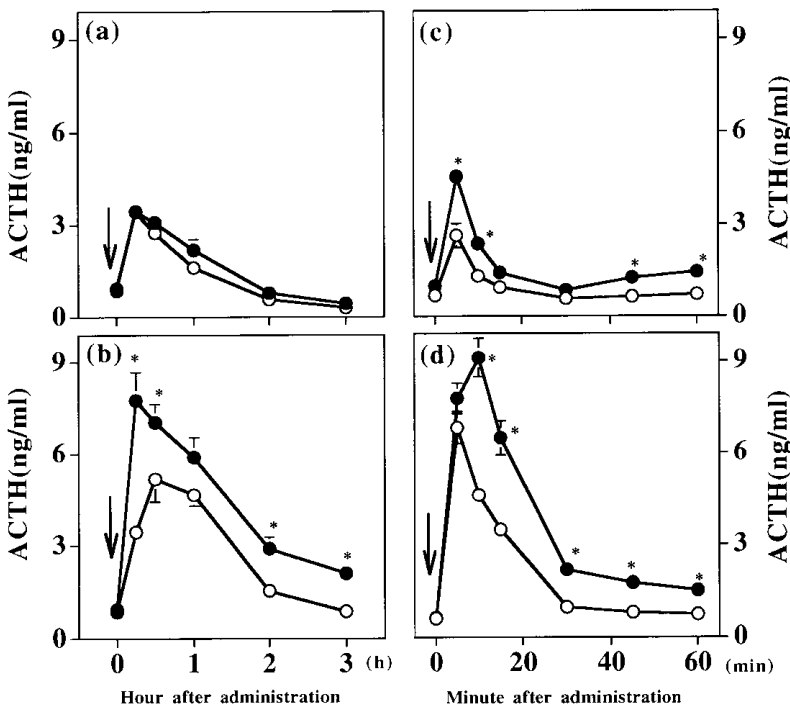

Figure 3 Plasma concentrations of ACTH in hypothyroid $(0)$ and control $(O)$ rats after a single i.v. administration of (a) $1 \mu \mathrm{g} \mathrm{CRH}$, (b) $10 \mu \mathrm{g} \mathrm{CRH}$, (c) $0.1 \mu \mathrm{g} \mathrm{AVP}$ and (d) $1 \mu \mathrm{g}$ AVP. Each point represents the mean \pm S.E.M. of five animals. Arrows represent the time of injection of $\mathrm{CRH}(\mathrm{a}, \mathrm{b})$ or AVP $(\mathrm{c}, \mathrm{d})$. Asterisks indicate $P<0.05$ compared with the value for the respective control analyzed using two-way ANOVA followed by Fisher's PLSD test.

hypothyroid rats was observed, whereas the increase in plasma level of corticosterone in response to immobilization stress was much smaller in hypothyroid than in control rats (Tohei et al. 1997). In the present study, decreases in adrenal weights and plasma concentrations of corticosterone, and increases in the plasma concentrations of ACTH were observed in hypothyroid male rats. These results suggest that hypothyroidism causes adrenal dysfunction directly and results in hypersecretion of ACTH.

In the present study, it is also demonstrated that the secretion of CRH and AVP in ME increased in hypothyroid rats compared with euthyroid rats using the push-pull perfusion technique, though the hypothalamus contents of $\mathrm{CRH}$ and AVP were not different between
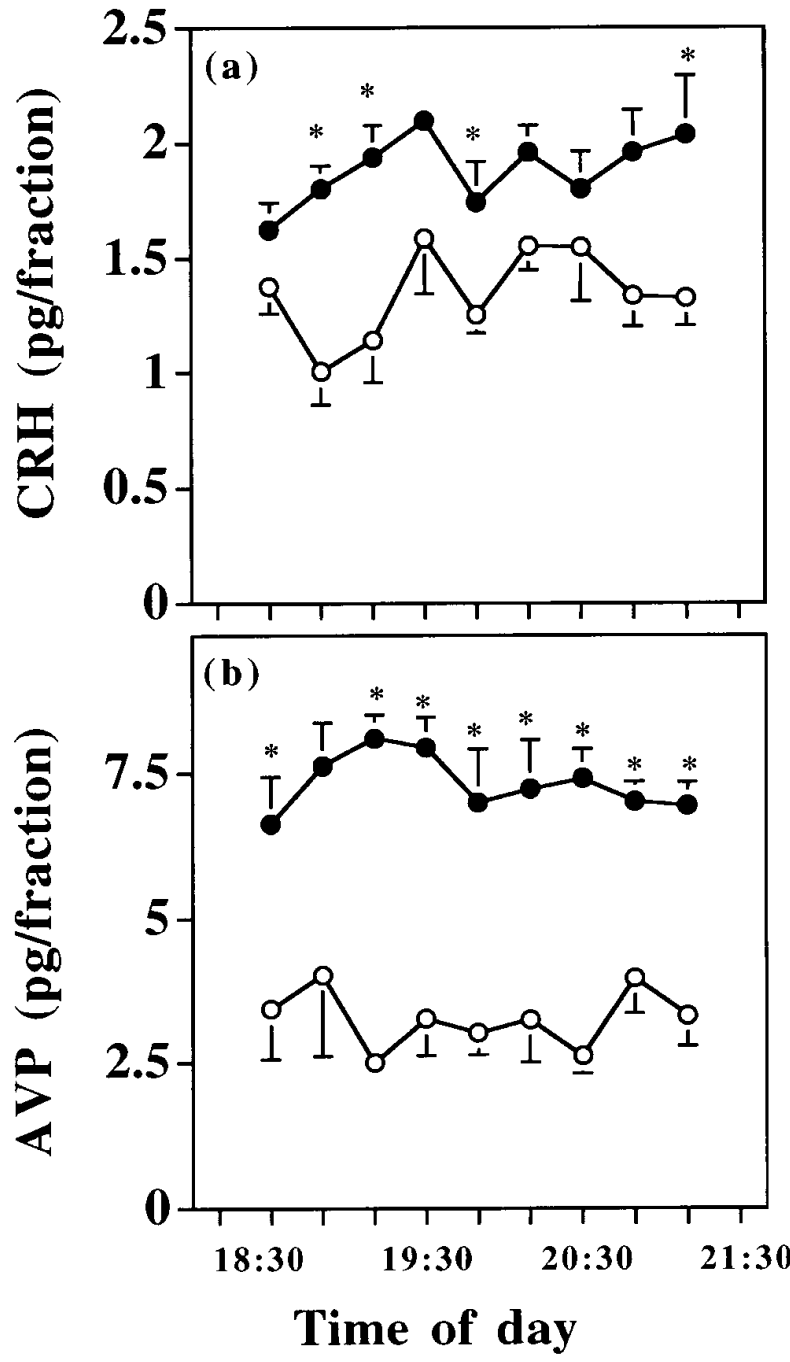

Figure 4 In vivo release of CRH (a) and AVP (b) in ME by push-pull perfusion in hypothyroid $(\bigcirc)$ and control $(\bigcirc)$ rats between 1830 and $2130 \mathrm{~h}$. Each point represents the mean \pm S.E.M. of five animals. Asterisks indicate $P<0.05$ compared with the value for the respective control analyzed using two-way ANOVA followed by Fisher's PLSD test.

the two groups. These results suggest that the synthesis of $\mathrm{CRH}$ and AVP in the hypothalamus probably increases in hypothyroid rats as compared with euthyroid rats. It has been known that $\mathrm{CRH}$ is a major physiological mediator of the hypothalamic control of ACTH secretion (Antoni 1986). In addition, it is also demonstrated that AVP amplifies the effect of $\mathrm{CRH}$ about 2- to 3-fold, and hence the slope of a dose-response curve for CRH or AVP alone will be less than that of AVP applied in combination with CRH (Gillies et al. 1982, Rivier \& Vale 1983, Vale et al. 1983). Several laboratories reported that CRH and AVP are colocalized in parvicellular neurons of the PVN (Roth et al. 1982, Tramu et al. 1983, Mouri et al. 1993). The 

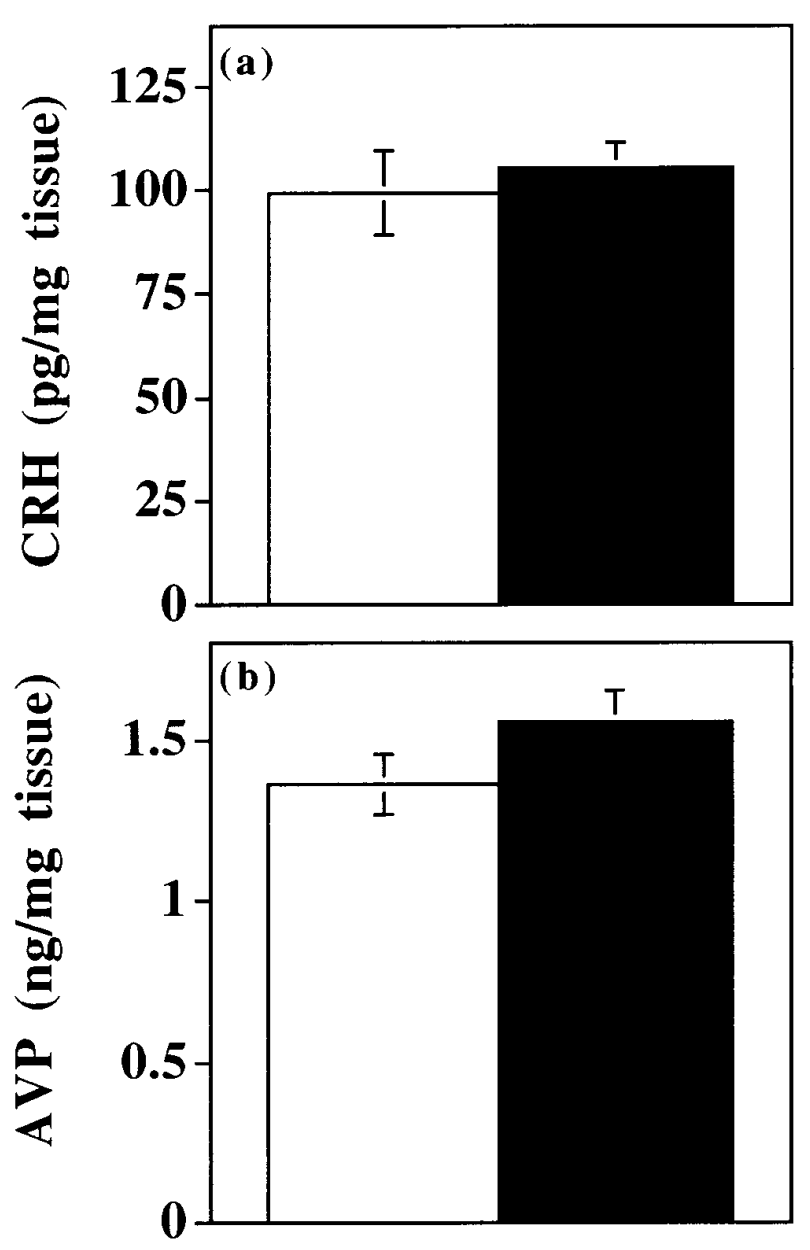

Figure 5 Hypothalamus concentrations of CRH (a) and AVP (b). Each bar represents the mean \pm S.E.M. of five animals.

co-expression of CRH and AVP in the neurons have been demonstrated in adrenalectomized rats (Kiss et al. 1984, Sawchenko et al. 1984) as a model of adrenal dysfunction. Adrenalectomy markedly increases the levels of $\mathrm{CRH}$ and AVP immunoreactivity (Antoni et al. 1983, Paull \& Gibbs 1983, Kiss et al. 1984), and the amount of mRNA transcripts of CRH and AVP gene (Wolfson et al. 1985, Antoni 1986, Davis et al. 1986) in the neurons of the PVN which contains glucocorticoid receptors in rats (Reul \& De Kloet 1985). It has also been reported that adrenalectomy increases the concentration of $\mathrm{CRH}$ and AVP in hypophysial portal blood (Oliver et al. 1983, Kooy et al. 1990) and the median eminence (Suda et al. 1983, Holmes et al. 1986). In the present study, it is clearly demonstrated that adrenal dysfunction causes the hypersecretion of $\mathrm{CRH}, \mathrm{AVP}$ and $\mathrm{ACTH}$ at the hypothalamus-pituitary level in hypothyroid male rats. In contrast to our results, a previous report by Shi et al. (1994) has shown that hypothyroidism causes a reduction in $\mathrm{CRH}$ gene transcripts in the PVN of male rats, with a concomitant decrease in both pro-opiomelanocortin (POMC) gene expression in the anterior pituitary gland and circulating corticosterone, though the plasma levels of POMC-related peptides were not reported. Although we cannot explain the differences between our results and those of Shi and colleagues we believe that the push-pull perfusion technique provides us with direct evidence that $\mathrm{CRH}$ and AVP release are increased from at least the ME.

In conclusion, hypothyroidism causes adrenal dysfunction directly, and results in hypersecretion of ACTH. The adrenal dysfunction leads to the hypersecretion of CRH and AVP from the hypothalamus in hypothyroid male rats. Therefore, reduced levels of thyroid hormone probably act on adrenal glands directly, and not at the hypothalamus-pituitary level.

\section{Acknowledgements}

We are grateful to the Rat Pituitary Hormone Distribution Program, NIDDK, NIH, Bethesda, MD, USA for providing RIA materials; Dr GD Niswender, Animal Reproduction and Biotechnology Laboratory, Colorado State University, Fort Collins, CO, USA for providing antisera to corticosterone (GDN B377); Dr M Suzuki, Gunma University, Maebashi, Japan for antisera to T3 and T4; Dr T Suda, Hirosaki University, Aomori, Japan for antisera to CRH; Dr R Hokao, The Imamichi Institute for Animal Reproduction, Ibaraki, Japan for Wistar rats and Dr J L Voogt, Department of Physiology, The University of Kansas Medical Center, KS, USA for the helpful suggestions. This work was supported by a grant-in-aid for Scientific Research from the Ministry of Education of Japan no. 0660375. A Tohei received a fellowship from the Japan Society for the Promotion of Science (JSPS).

\section{References}

Antoni FA 1986 Hypothalamic control of adrenocorticotropin secretion: advances since the discovery of 41-residue corticotropinreleasing factor. Endocrine Reviews 7 351-378.

Antoni FA, Parcovits M, Makara GB, Linton EA, Lowry PJ \& Kiss JZ 1983 Immunoreactive corticotropin releasing hormone (CRF) in the hypothalamo-infundibular tract. Neuroendocrinology 36 415-423.

Boler RK \& Moore NA 1982 Depression of adrenocortical function by pharmacologic doses of thyroxine in intact and unilaterally adrenalectomized rats. Hormone Research 16 209-218.

Canny BJ, Smith AI, Clements JA \& Funder JW 1988 Posttranslational processing of pro-opiomelanocortin in the Brattleboro (di/di) rat pituitary. Neuroendocrinology 48 603-610.

Davis LG, Arentzen R, Reid JM, Mannig RW, Wolfson B, Lawrence KL \& Baldino F 1986 Glucocorticoid sensitivity of vasopressin mRNA levels in paraventricular nucleus of the rat. Proceedings of the National Academy of Sciences of the USA 83 1145-1149.

Gillies GE, Linton EA \& Lowry PJ 1982 Corticotropin releasing activity of the new CRF is potentiated several times by vasopressin. Nature 299 355-357.

Holmes MC, Antoni FA, Catt KJ \& Aguilera G 1986 Predominant release of vasopressin vs corticotropin releasing factor from the isolated median eminence after adrenalectomy. Neuroendocrinology 43 $245-251$ 
Kamilaris TC, DeBold CR, Johnson EO, Mamalaki E, Listwak SJ, Calogero AE, Kalogeras KT, Gold PW \& Orth DN 1991 Effects of short and long duration hypothyroidism and hyperthyroidism on the plasma adrenocorticotropin and corticosterone responses to ovine corticotropin-releasing hormone in rats. Endocrinology 128 2567-2576.

Kanesaka T, Taya K \& Sasamoto S 1992 Radioimmunoassay of corticosterone using ${ }^{125}$ I-labeled radioligand. Journal of Reproduction and Development 38 85-89.

Kiss JZ, Mezey E \& Skirboll L 1984 Corticotropin-releasing factor immunoreactive neurons of the paraventricular nucleus become vasopressin positive after adrenalectomy. Proceedings of the National Academy of Sciences of the USA 81 1854-1858.

Kooy A, de Greef WJ, Vreeburg JTM, Hackeng WHL, Ooms MP, Lamberts SWJ \& Weber RFA 1990 Evidence for the involvement of corticotropin-releasing factor in the inhibition of gonadotropin release induced by hyperprolactinemia. Neuroendocrinology $\mathbf{5 1}$ 261-266.

McCarthy JL, Corley RC \& Zarrow MX 1959 Effect of goitrogens on adrenal glands of rats. American Journal of Physiology 197 693-698.

Mouri T, Itoi K, Takahashi K, Suda T, Murakami O, Yosinaga K, Andoh N, Ohtani H, Masuda T \& Sasano N 1993 Colocalization of corticotropin-releasing factor and vasopressin in the paraventricular nucleus of the human hypothalamus. Neuroendocrinology 57 34-39.

Murakami N, Hayafuji C \& Takahashi K 1984 Thyroid hormone maintains normal circadian rhythm of blood corticosterone levels in the rat by restoring the release and synthesis of ACTH after thyroidectomy. Acta Endocrinologica 107 519-524.

Oliver C, Conte-Devolx B, Rey M, Boudouresque F, Giraud P, Castanas E \& Porter JC 1983 Immunoreactive 41-CRF in hypophysial portal blood of intact and adrenalectomized rats. Acta Endocrinologica 103 (Suppl 256) 98.

Paull WK \& Gibbs FP 1983 The corticotropin releasing factor(CRF) neurosecretory system in intact, adrenalectomized and adrenalectomized-dexamethasone treated rats. Histochemistry $\mathbf{7 8}$ 303-316.

Paxinos G \& Watson C 1986 The Rat Brain in Stereotaxic Coordinates, edn 2. Australia: Academic Press.

Reul JMHM \& De Kloet ER 1985 Two receptor systems for corticosterone in rat brain: microdistribution and differential occupation. Endocrinology 117 2505-2511.

Rivier C \& Vale W 1983 Interaction of corticotropin-releasing factor and arginine vasopressin on adrenocorticotropin secretion in vivo. Endocrinology 113 939-942.

Roth KA, Weber E \& Barchas JD 1982 Immunoreactive corticotropin releasing factor $(\mathrm{CRH})$ and vasopressin are colocalized in a subpopulation of the immunoreactive vasopressin cells in the paraventricular nucleus of the hypothalamus. Life Sciences $\mathbf{3 1}$ 1857-1860.

Sawchenko PE, Swanson LW \& Vale WW 1984 Coexpression of corticotropin-releasing factor and vasopressin immunoreactivity in parvocellular neurosecretory neurons of the adrenalectomized rats. Proceedings of the National Academy of Sciences of the USA $\mathbf{8 1}$ $1883-1887$.

Shi ZX, Levy A \& Lightman SL 1994 Thyroid hormone-mediated regulation of corticotropin releasing hormone messenger ribonucleic acid in the rat. Endocrinology 134 1577-1580.

Suda T, Tomori N, Tozawa F, Mouri T, Demura H \& Shizume K 1983 Effects of bilateral adrenalectomy on immunoreactive corticotropin-releasing factor in the rat median eminence and intermediate-posterior pituitary. Endocrinology 113 1182-1184.

Suda T, Tomori N, Yajima F, Sumitomo T, Nakagami Y, Ushiyama T, Demura H \& Shizume K 1987 Time course study on the effect of reserpine on hypothalamic immunoreactive CRF levels in rats. Brain Research 405 247-252.

Tohei A, Akai M, Tomabechi T, Mamada M \& Taya K 1997 Adrenal and gonadal function in hypothyroid adult male rats. Journal of Endocrinology 152 147-154.

Tomabechi T, Taya K, Akai M \& Sasamoto S 1994 A radioimmunoassay for adrenocorticotropic hormone (ACTH) in unextracted plasma of various animals. Journal of Reproduction and Development $\mathbf{4 0}$ 99-104.

Tramu G, Croix C \& Pillez A 1983 Ability of the CRF immunoreactive neurons of the paraventricular nucleus to produce a vasopressin-like material. Neuroendocrinology 37 467-469.

Vale W, Vaughan J, Smith M, Yamamoto G, Rivier J \& Rivier C 1983 Effects of synthetic ovine corticotropin-releasing factor, glucocorticoids, catecholamines, neurohypophysial peptides and other substances on cultured corticotropic cells. Endocrinology 113 $1121-1131$.

Watanobe H \& Takebe K 1994 Effects of intravenous administration of interleukin-1-beta on the release of prostaglandin E2, corticotropin-releasing factor, and arginine vasopressin in several hypothalamic areas of freely moving rats: estimation by push-pull perfusion. Neuroendocrinology 60 8-15.

Wolfson B, Manning RW, Davis LG \& Arentzen R 1985 Co-localization of corticotropin releasing factor and vasopressin mRNA in neurones after adrenalectomy. Nature 317 59-61.

\section{Received 9 January 1997}

Revised manuscript received 23 May 1997

Accepted 16 September 1997 